УдК 159.9:331.101.3

\title{
И.И. Черемискина
}

Владивостокский государственный университет экономики и сервиса Владивосток. Россия

\section{Черты личности судей на разных этапах профессионализации}

\begin{abstract}
Профилактика неблагоприятных состояний, связанных с особыми условиями профессиональной деятельности, является одной из приоритетных задач психологии труда. Судебная система в Российской Федерации выполняет роль общественного арбитра и защищает все сферы деятельности, регулируемые правом, однако в этой системе работают обычные люди, на которых возлагается высокая моральная ответственность. Скорее всего, выбор такого рода профессиональной деятельности обусловлен различными субъективными факторами, в частности, особыми личностными качествами, которые в процессе длительного выполнения профессиональных обязанностей могут принимать форму профессиональных деформаций, что, в свою очередь, снижает уровень их профессиональной эффективности. В статье представлен сравнительный анализ личностных качеств и интеллектуальных способностей судей, находящихся на разных этапах профессионализации, а именно: кандидатов на должность и судей со стажем от 3 лет. Использованы результаты реальной профессиональной диагностики с помощью рекомендованных для этой процедуры психодиагностических методик. Обнаруженные различия позволяют предположить, что в процессе профессионализации у судей обостряются некоторые черты личности и развиваются определенные интеллектуальные способности. Результаты в теоретическом плане дополняют научные представления о формировании в профессии специфически-профессионального типа личности, а в практическом являются основой для разработки и реализации в судебной системе психологических профилактических мероприятий.
\end{abstract}

Ключевые слова и словосочетания: тенденции, экономический рост, анализ экономики, оценка тенденций экономики, цепочка добавленной стоимости, Upstreamness.

\section{I.I. Cheremiskina}

Vladivostok State University of Economics and Service

Vladivostok. Russia

Черемискина Ирина Игоревна - канд. психол. наук, доцент кафедры философии и юридической психологии; e-mail: irina-cheremiski@mail.ru 


\title{
Personality traits of judges at the different stages of professionalization
}

\begin{abstract}
Prevention of adverse conditions associated with special conditions of professional activity is one of the priority tasks of the labor psychology. The judicial system in the Russian Federation plays the role of public arbitrator and protects all spheres of activity regulated by law, but this system consists from the ordinary people who have a high moral responsibility. The choice of this type of professional activity is likely due to various subjective factors, in particular special personal qualities, which in the process of long-term performance of professional duties can take the form of professional deformation, which in turn reduces their level of professional efficiency. The article presents a comparative analysis of the personal qualities and intellectual abilities of judges at different stages of professionalism, namely candidates for office and judges with experience of 3 years. The results of real professional diagnostics using diagnostic methods recommended for this procedure are used. The differences found suggest that in the process of professionalization judges escalate some personality traits and develop specific intellectual abilities. The results in theoretical terms can add scientific ideas about the formation of a specific professional type of personality in the profession and in practical terms - to be the basis for the development and implementation of psychological preventive measures in the judicial system.
\end{abstract}

Keywords: personality traits, professional deformation, judges.

Система судебных органов обеспечивает незыблемость основ конституционного строя, охраняя правопорядок, единство экономического пространства, имущественные и неимущественные права граждан и юридических лиц, а также гарантирует свободу экономической деятельности [6]. Стратегическая роль судебной системы в современной модернизации нашего государства и общества заключается в том, что она, с одной стороны, призвана гарантировать реальность прав и свобод человека и гражданина, с другой - обеспечить действие других ветвей государственной власти - законодательной и исполнительной в рамках правового пространства Конституции Российской Федерации.

Центральной фигурой судебной власти является судья. Именно он уполномочен выступать как представитель Закона и Государства. Его деятельность сложна, ответственна и многогранна в связи с разнообразием выполняемых им функций и решением комплекса правоприменительных задач. Судья - юрист высшей квалификации, наделенный правом вершить правосудие.

Юридически судья представляет собой третью ветвь государственной власти. Его главная цель, обязанность и миссия - строго следовать букве закона (Конституции). Он не подотчетен более никому, принимает решения самостоятельно, что определяет не только огромную ответственность, но и безусловный авторитет [1].

Судьей может быть гражданин Российской Федерации, имеющий высшее юридическое образование, не имеющий (имевший судимости), не имеющий гражданства иностранного государства, не состоящий на учете в наркологическом и психоневрологическом диспансере, в возрасте от 25 лет (мировой/федеральный суд), 30 лет (Арбитражный суд), 35 лет (Верховный), 40 лет (Конституционный). К человеку, претендующему на должность судьи, предъявляют и другие социальные, психофизиологические и психологические требования. 
Статус судей Российской Федерации является комплексным правовым институтом, призванным обеспечивать в условиях реальной жизни независимость судей Российской Федерации от внешнего воздействия и предоставление судье и членам его семьи достойные условия существования.

Деятельность судьи исключительно сложна и многообразна, но в то же время составные компоненты ее сравнительно устойчивы и в своей основе проявляются в каждом рассматриваемом уголовном и гражданском деле. Это постоянство деятельности помогает процессу образования, воспитания у судьи таких психических качеств, которые в наибольшей степени соответствуют выполняемым им функциям.

Условия и содержание профессиональной судебной деятельности, высокая социальная значимость её результатов обусловливают целый комплекс требований к психическим свойствам судьи. Рассмотрение психологической структуры судебной деятельности дает основу для выявления тех качеств, которыми должен обладать судья для выполнения всех функций, всех видов деятельности, реализующихся в суде. Такие качества в психологии труда называются профессионально важными. В.А. Толочек, говоря о способностях человека к профессиональной деятельности, определяет их как внутренние психологические характеристики субъекта, в которых присутствуют внешне специфические воздействия, являющиеся формой требования профессии к человеку [8]. По мнению В.В. Скорочан, профессионально важные качества влияют на эффективность труда.

Различные авторы подчёркивают, что судьям необходимо отличаться самоконтролем, эмоциональной сдержанностью, умением сохранять спокойствие в напряженных ситуациях, требовательностью к форме поведения и высказываниям участвующих лиц, и вместе с тем указывают на важность проявления терпимости, тактичности, способности к снижению чрезмерной напряжённости течения судебного процесса, эмоционального возбуждения его участников. Прежде всего, судья должен осознавать и обладать высокой степенью ответственности за свою деятельность, за принятые решения и все последствия реализации принятых им решений [7].

Постоянная ответственность судьи перед обществом предельно стимулирует его познавательные способности, анализ всей получаемой информации требует от него четкости и ясности в принятии решений.

Изучение специфики профессиональной деятельности дает возможность описания личностных и профессионально важных качеств судьи, с целью учета в процессе профессиональной подготовки и оптимизации системы профессионального отбора [4].

Эффективная работа судебных работников охватывает множество специфик. В своей деятельности судьи должны опираться не только на правовые, юридические и законные нормы, но и на нормы социальные, напрямую связанные с этикой работы, и теми психологическими качествами и приемами, которыми должен владеть судья. Специфика профессиональной деятельности судьи, требующая действовать гибко и решительно, предполагает наличие направленности личности судьи на реализацию норм закона, права и тех требований, которые накладываются социальными императивами, что также должно сочетаться с наличием профессиональной осознанности, пониманием ценностей профессии, долга, постоянным ростом и развитием профессиональных навыков, готовностью к повышению судебной культуры. 
Такие высокие требования, связанные с безупречным знанием норм закона и психологических особенностей людей, направлены на соблюдение объективности суда, рассмотрение дела во всех его аспектах. Постоянное подтверждение квалификации нацелено на поиск признаков профессионального выгорания, регулирование судебных ошибок и образование значимых качеств работников.

Все эти повышенные требования к осуществлению профессиональной деятельности могут приводить к формированию профессиональной деформации.

По общему определению профессиональная деформация личности представляет собой изменения, происходящие в личности под влиянием какой-либо профессии. Ввиду такого широкого понимания развитие профессиональных качеств и умений трактуется как профессиональные деформации. Е.В. Дворцова и Е.В. Литвиненко, изучая профессиональную деформацию работников прокуратуры, отмечают, что данный феномен целесообразно понимать как изменение сложившейся психологической структуры личности в процессе профессионального труда при переносе такого профессионального поведения во внепрофессиональные сферы [3]. Е.П. Ильин в качестве причин профессиональной деформации судей обозначает затруднения в ограничении их власти, а также отсутствие общественного контроля и критики [5].

Деформация проявляется не сразу, и быстрота её наступления зависит от множества факторов, большинство из которых связано непосредственно с человеком, осуществляющим свою профессиональную деятельность. Она может влиять на уровень профессиональной ценностной сформированности у человека, осознание себя в профессии, осознание долга и прочее. Повышенная тревожность, противодействие, истощение приводят к профессиональной деформации, которая затрагивает все аспекты психической деятельности человека, воздействуя как на мыслительные процессы, так и на эмоциональный полюс человека.

Все рабочие особенности, связанные с однообразностью процесса, длительностью и монотонностью труда, приводят к приобретению таких негативных черт, как пессимистичность, негативизм, ухудшение работоспособности, утрата интереса, нежелание осваивать новые инструменты, коммуникативные барьеры. Ввиду личностных особенностей, ценностных установок, профессиональных амбиций, ориентации на труд для каждого человека период формирования профессиональной деформации может отличаться и происходить на любом этапе профессиональной деятельности. Профессиональная деформация в любом проявлении, даже имея незначительный характер, негативно сказывается на эффективности осуществления профессиональной деятельности, возможности личностного и профессионального роста человека.

Одним из наиболее опасных следствий профессиональной деформации личности судьи выступает чрезмерная подозрительность. Возможна, например, ситуация, когда судья выносит подсудимому необоснованно суровый приговор, не соответствующий содеянному. Результатом профессиональной деформации могут быть изменения психофизиологических и характерологических качеств судьи. Тем не менее, профессиональная деформация не обязательный признак судебной деятельности, ее появление можно предупредить. Здесь важную роль играют система строгого соблюдения морально-нравственных правил поведения судьи, правильная организация труда, общение с людьми неюридической профессии и т.д. 
Судья должен уметь владеть собой, заниматься самовоспитанием, самоанализом, положительно относиться к критике. Ему должно быть присуще качество здоровой самокритичности. Очень важна психологическая помощь в профилактике профессиональных деформаций у судей, включающая психологическое сопровождение в виде когнитивной и рациональной консультационной терапии с целью развития саногенного мышления и отказа от экстрапунитивных установок [2].

Оценкой профессиональных качеств в судебной системе занимаются психологи. В роли методического инструмента используются рекомендованные психодиагностические методики. В нашем исследовании были использованы данные психодиагностики, собранные с 2016 года, проанализированы результаты 80 человек, из них 40 судей со стажем в возрасте от 32 до 55 лет с опытом работы в данной должности от 3 до 10 лет. Вторая группа испытуемых - 40 кандидатов на должность судьи в возрасте от 28 лет до 45 лет. Таким образом, схема эмпирического исследования носит псевдолонгитюдный характер. Безусловно, такой подход не дает возможности говорить об индивидуальных изменениях, но представляется единственно возможным в данных условиях. Предметом исследования послужили черты личности судей, особое внимание было обращено на интеллектуальные способности, поскольку их изменения в процессе профессионализации прогнозируются на основе теоретического анализа. Для оценки обозначенного предмета в качестве диагностических методик были выбраны: стандартизированный метод исследования личности (СМИЛ), адаптированный Л.Н. Собчик, и тест структуры интеллекта Р. Амтхауэра.

Обработка результатов методики СМИЛ с помощью построения группового профиля на основе средних значений шкальных оценок в двух группах показала его «линейный тип» и отсутствие выраженных акцентуаций. Однако оценка индивидуальных показателей позволила получить результаты, превышающие норму, на этой основе был применен расчет моды индивидуальных показателей респондентов в двух группах. Полученные данные представлены в табл.

Таблииа

Результаты расчета моды для каждого признака по методике «Стандартизированный метод исследования личности» среди судей двух исследуемых групा

\begin{tabular}{|c|c|c|c|c|c|c|c|c|c|c|}
\hline Шкалы & $\begin{array}{c}\text { Ипо- } \\
\text { хон- } \\
\text { дрия }\end{array}$ & $\begin{array}{c}\text { Трево- } \\
\text { га }\end{array}$ & $\begin{array}{c}\text { Эмоци- } \\
\text { ональ- } \\
\text { ная } \\
\text { лабиль- } \\
\text { ность }\end{array}$ & $\begin{array}{c}\text { Пси- } \\
\text { хоптия }\end{array}$ & $\begin{array}{c}\text { Маску- } \\
\text { лин- } \\
\text { ность }\end{array}$ & $\begin{array}{c}\text { Пара- } \\
\text { ноид- } \\
\text { ность }\end{array}$ & $\begin{array}{c}\text { Пси- } \\
\text { хас- } \\
\text { те- } \\
\text { ния }\end{array}$ & $\begin{array}{c}\text { Шиз- } \\
\text { ид- } \\
\text { ность }\end{array}$ & $\begin{array}{c}\text { Гипо } \\
\text { ма- } \\
\text { ния }\end{array}$ & $\begin{array}{c}\text { Соци- } \\
\text { наль- } \\
\text { ная } \\
\text { интро- } \\
\text { версия }\end{array}$ \\
\hline \multicolumn{8}{|c|}{ Судьи со стажем } \\
\hline Мода & 52 & 52 & 47 & 63 & 62 & 50 & 49 & 52 & 50 & 49 \\
\hline
\end{tabular}


Представленные данные показывают, что у судей со стажем высокая частота встречаемости повышенных значений по шкалам «маскулинность» и «психопатия». Таким образом, для судей со стажем работы преимущественно характерен стенический склад личности, проявляющийся в высокой психической активности, воле и высокой самооценке. В структуре мотивационной направленности у них преобладают мотивация достижения, уверенность и быстрота принятия решения. Также им могут быть свойственны нетерпеливость и склонность к риску, проявление конфликтности в личностно значимых ситуациях. Типичным защитным механизмом для них является вытеснение неприятной или угрожающей самооценки информации, что может сопровождаться реакциями на поведенческом уровне (например, в критических высказываниях), и снижает риск психосоматических проявлений.

Повышенные значения по шкале «маскулинность» наблюдаются только у женщин-судей со стажем, прошедших психологическую диагностику. В целом в первой группе их две трети выборки (28 человек). Такие результаты могут свидетельствовать о том, что женщины-судьи со стажем демонстрируют независимый тип поведения, по мужскому, агрессивному образцу.

Что касается группы кандидатов на должность судьи, то и здесь наблюдается повышение значений по шкале «макскулинность» у женщин, которых в выборке 25 из 40. Следовательно, для них также характерна высокая самостоятельность в принятии решений.

Результаты двух сравниваемых групп по данной методике были обработаны с помощью статистического критерия U-Манна-Уитни в программе SPSS 20.0. На основе проведенного сравнения выявлены значимые различия в показателях по шкалам «эмоциональная лабильность» и «шизоидность» на уровне статистической значимости 0,01 . Установленные различия свидетельствуют о таких особенностях поведения судей со стажем, как высокая социальная гибкость, способность к перевоплощению и демонстративности. При этом судьи со стажем при принятии решений в большей степени ориентированы на свои внутренние критерии, чем мнение окружающих, отличаются большей вдумчивостью и независимостью взглядов.

Тест структуры интеллекта Р. Амтхауэра представляет собой 9 групп заданий, ориентированных на изучение следующих составляющих вербального и невербального интеллекта: лексический запас, способность к абстрагированию, способность к обобщению, математические способности, комбинаторное мышление, пространственное воображение, способность к кратковременному запоминанию наглядно-образной информации. Так, на основании статистической обработки данных получены достоверные (на уровне 0,01 ) различия результатов двух групп по шкалам «исключение слов», «числовые ряды» и «вращение кубиков». Что означает повышенные способности судей со стажем, по сравнению с кандидатами на должность судьи, к точному и реактивному выражению словесных значений, развитое индуктивное и аналитико-синтетическое мышление, а также конструктивность теоретических и практических способностей. 
В результате можно сделать следующие выводы.

Во-первых, зафиксированы схожие личностные черты, выраженные как у кандидатов в судьи, так и у судей со стажем, в частности маскулинность у женщин. Другими словами, стремление к самостоятельности и независимости в принятии решений является специфической профессиональной чертой личности работников судебной системы, не связанной со стажем судейской деятельности.

Во-вторых, у судей со стажем обнаружены личностные черты, выраженность которых отличается от кандидатов в судьи, их можно назвать профессионально специфичными, развивающимися со стажем, а именно: преобладание мотивации достижения и уверенности в себе, ориентация на внутренние критерии при принятии решений, независимость от мнения окружающих при высокой социальной гибкости и демонстративности.

В-третьих, у судей со стажем формируются мыслительные способности, связанные со спецификой профессиональной деятельности, а именно: аналитико-синтетические при высокой гибкости и реактивности вербальных способностей. Полученные эмпирические данные соотносятся с данными теоретического анализа и позволяют говорить о личностных изменениях судей в процессе длительного выполнения ими профессиональных обязанностей. Однако такие особенности скорее говорят о профессиональном развитии, чем о профессиональных деформациях. Связано это как с тем, что акцентуации не превышают норму, так и с особенностями самого исследования, которые не позволяют оценить степень проявления этих черт во внепрофессиональной деятельности судей.

Проведенное исследование отличается сложностью эмпирической выборки, доступ к которой зачастую ограничен. Полученные результаты позволяют подтвердить теоретические положения о связи личностных изменений со спецификой профессиональной деятельности, в частности работников судебной системы, имеют практическое значение в контексте диагностики и профилактики профессиональных деформаций конкретных специалистов (судей), так как перед психологами в судебной системе актуальной является задача профессионального отбора, но полученные результаты могут рассматриваться и в динамике, демонстрируя глубину личностных изменений.

1. Васильев В.Л. Юридическая психология. - Санкт-Петербург: Питер, 2006. - 609 с.

2. Горобец Т.Н., Кечил Д.И. Профессиональная деформация юристов и методы профилактики // Психология XXI века: вызовы, поиски, векторы развития. - Рязань: Академия права и управления Федеральной службы исполнения наказаний, 2019. С. 729-743.

3. Дворцова Е.В., Литвиненко Е.В. Изучение профессиональной деформации сотрудников прокуратуры // Ананьевские чтения.- Санкт-Петербург, 2007. Вып. 1. C. $440-442$.

4. Зуева Л. Ю. Личностные и профессионально важные качества как основа профессиональной компетентности дознавателя. - Текст: электронный // Психопедагогика в правоохранительных органах. 2009. №1 // Cyberleninka: [сайт].- URL: https://cyberleninka.ru/article/n/lichnostnye-i-professionalno-vazhnye-kachestva-kakosnova-professionalnoy-kompetentnosti-doznavatelya (дата обращения: 18.02.2020).

5. Ильин Е. П. Работа и личность. Трудоголизм, перфекционизм, лень.- СанктПетербург: Питер, 2011. - 224 с. 
6. Клишас А. А. Теория судебного права и организации судебных систем. - Москва: ИНФРА-М, 2018. - 348 с.

7. Столяренко О.М. Психологические приемы в работе юриста. - Москва: Юрайт, 2006. 288 c.

8. Толочек В.А. Современная психология труда. - Санкт-Петербург: Питер, 2010. - 432 с.

\section{Транситерация}

1. Vasil'ev V.L. Yuridicheskaya psihologiya. - Sankt-Peterburg: Piter, 2006. - 609 p.

2. Gorobec T. N., Kechil D. I. Professional'naya deformaciya yuristov i metody profilaktiki // Psihologiya HKHI veka: vyzovy, poiski, vektory razvitiya. - Ryazan': Akademiya prava i upravleniya Federal'noj sluzhby ispolneniya nakazanij, 2019. P. 729-743.

3. Dvorcova E. V., Litvinenko E. V. Izuchenie professional'noj deformacii sotrudnikov prokuratury // Anan'evskie chteniya. - Sankt-Peterburg, 2007. Vyp. 1. P. 440-442.

4. Zueva L. Yu. Lichnostnye i professional'no vazhnye kachestva kak osnova professional'noj kompetentnosti doznavatelya. - Tekst: elektronnyj // Psihopedagogika V pravoohranitel'nyh organah. 2009. №1 // Cyberleninka: [sajt]. - URL: https://cyberleninka.ru/article/n/lichnostnye-i-professionalno-vazhnye-kachestva-kakosnova-professionalnoy-kompetentnosti-doznavatelya (data obrashcheniya: 18.02.2020).

5. Il'in E. P. Rabota i lichnost'. Trudogolizm, perfekcionizm, len'. - Sankt-Peterburg: Piter, 2011. - 224 p.

6. Klishas A.A. Teoriya sudebnogo prava i organizacii sudebnyh sistem. - Moskva: INFRAM, 2018. -348 p.

7. Stolyarenko O. M. Psihologicheskie priemy v rabote yurista. - Moskva: Yurajt, 2006. $288 \mathrm{p}$.

8. Tolochek V.A. Sovremennaya psihologiya truda. - Sankt-Peterburg: Piter, 2010. - 432 p.

(С) И.И. Черемискина, 2020

Для цитирования: Черемискина И.И. Черты личности судей на разных этапах профессионализации // Территория новых возможностей. Вестник Владивостокского государственного университета экономики и сервиса. 2020. Т. 12, № 1. С. 145-152.

For citation: Cheremiskina I.I. Personality traits of judges at the different stages of professionalization, The Territory of New Opportunities. The Herald of Vladivostok State University of Economics and Service, 2020, Vol. 12, № 1, pp. 145-152.

DOI dx.doi.org/10.24866/VVSU/2073-3984/2020-1/145-152

Дата поступления: 21.02.2020. 